\title{
Comprehensive Control Method of Gas in Upper Corner of High Strength Fully Mechanized Coal Mine
}

\author{
Huijun Duan ${ }^{1,2}$, Shijun Hao ${ }^{1,2}$ and Xu Peng ${ }^{1,2}$ \\ ${ }^{1}$ China Coal Research Institute, Beijing 100013, China; \\ ${ }^{2}$ Xi'an Research Institute, China Coal Technology and Engineering Group, Xi'an 710077, China
}

\begin{abstract}
Based on the problem of large gas emission and serious gas accumulation in upper corner of the intensive fully mechanized caving face, taking the fully mechanized caving face of Wangjialing Coal Mine in Hedong Mine as the research object, the main gas emission sources of the extremely intensive mining face with low permeability and low gas content were studied. The methods of gas extraction by inserting (burying) pipe in upper corner and directional drilling in upper corner were adopted and carried out. The application of engineering practice and comparative test of effect are carried out. The results show that the maximum extraction purity is $2.8 \mathrm{~m}^{3} / \mathrm{min}$, the maximum gas concentration is $0.8 \%$ in upper corner, 3.11 $\mathrm{m}^{3} / \mathrm{min}$ in the high directional borehole and $0.71 \%$ in upper corner. After combined extraction, the total extraction purity is $1.33 \sim 7.93 \mathrm{~m}^{3} / \mathrm{min}$ and the fluctuation range of gas concentration in upper corner is reduced to $0.31 \sim 0.61 \%$ safe point. The effect of gas prevention and control in working face is remarkable.
\end{abstract}

\section{Introduction}

Under the conventional mining conditions, according to the gas drainage theory of pressure relief and permeability enhancement, the constitutive theory of gas flow around the drainage borehole and the "O" ring theory of gas drainage, etc ${ }^{[1-5]}$, The measures of strengthening pre drainage before mining, increasing permeability of coal seam, drilling through layers, hanging wind barrier and wind wall and other control measures have achieved certain effect on gas control in upper corner ${ }^{[6]}$. However, in super mining mine, the permeability of coal seam is low, the permeability coefficient is small, and the gas content of coal seam is small. The pre drainage effect is not ideal before mining, and there is no obvious effect after using the pre splitting technology of coal seam ${ }^{[7]}$. The wind barrier and wind wall are temporary measures, and there is a problem of short effective hole section in cross layer drilling. At the same time, the ultra strong mining face has large mining intensity and large coal output, and the single-sided single-day round shift output is more than $10000 \sim 20000$ $\mathrm{t}$, which leads to high gas emission from coal cutting and goaf left over coal seams, resulting in gas problems in the upper corner of super mining face.

\section{Engineering background}

The 322 working face of No.2 Coal Seam in Wangjialing coal mine is located in the north of the east wing of 123 panel, with a strike length of $3307 \mathrm{~m}$ and a dip length of
304.8 M. The average thickness of coal seam is $6.5 \mathrm{M}$. The average daily coal cutting is more than $5 \mathrm{~m}$ and the average daily output is more than $12000 \mathrm{~T}$. The Super mining results in the gas concentration of $0.6 \sim 0.8 \%$ in the upper corner of the working face, and the gas over warning phenomenon often occurs.

\section{Gas source analysis of super mining face}

The main sources of gas in super strong mining face are long-term natural gas analysis of belt and coal wall of return air roadway in fully mechanized mining face, release and emission of coal cut and top coal caving by coal shearer, analysis of coal loss in goaf and gas release from adjacent strata ${ }^{[7-11]}$.

The analysis of gas emission from top coal caving with coal cutting machine, the analysis of coal loss in goaf and the gas emission amount of adjacent seam are important aspects of analysis. According to AQ1018-2006 prediction method of mine gas emission, the relative gas emission of fully mechanized working face, the gas emission of mining coal seam, the gas emission near the working face and the gas emission in goaf can be calculated by the following formula ${ }^{[12]}$.

$$
Q_{H}=Q_{K}+Q_{L}
$$

Formula: $Q_{H}$, gas emission in fully mechanized coal face, $\mathrm{m}^{3} / \mathrm{t} ; Q_{K}$, gas emission of coal seam, $\mathrm{m}^{3} / \mathrm{t} ; Q_{L}$, gas emission from adjacent strata of working face, $\mathrm{m}^{3} / \mathrm{t}$.

1) Gas emission from coal seam

$$
Q_{K}=k_{1} k_{2} k_{3} \cdot \frac{m}{m_{0}}\left(x-x_{c}\right)
$$


Formula: $Q_{K}$, relative gas emission of coal seam, $\mathrm{m}^{3} / \mathrm{t}$; $k_{1}$, gas emission coefficient of surrounding rock of working face, $k_{l}=1.30 ; k_{2}$, gas emission coefficient of lost coal in mining, $k_{2}=1.13 ; k_{3}$, influence coefficient of roadway pre draining gas on coal face gas emission.

$$
k_{3}=\frac{L-2 h}{L}
$$

Formula: $L$, length of working face, $\mathrm{m} ; H$, equivalent width of Roadway Gas Pre drainage, $\mathrm{m} ; M$, coal seam thickness of working face, $\mathrm{m} ; m_{0}$, mining thickness of coal seam in working face, $\mathrm{m}$; $x$, original gas content of coal, $\mathrm{m}^{3} / \mathrm{t}, x=3.24 \mathrm{~m}^{3} / \mathrm{t} ; x_{c}$, residual gas content of coal, $\mathrm{m}^{3} / \mathrm{t}, x_{c}=2.60 \mathrm{~m}^{3} / \mathrm{t}$.

The gas emission of coal seam is calculated: $Q_{\mathrm{K}}=$ $1.78 \mathrm{~m}^{3} / \mathrm{t}$.

2) Gas emission from adjacent layers

$$
Q_{L}=\sum_{i=1}^{n} \frac{m_{i}}{m_{0}} k_{i} \bullet\left(\mathrm{x}_{i}-x_{i c}\right)
$$

Formula: $\mathrm{Q}_{\mathrm{L}}$, gas emission from adjacent strata of working face, $\mathrm{m} 3 / \mathrm{t}$; mi, It is the thickness of the i-th adjacent seam, and the thickness of $3 \#$ and $10 \#$ coal seams is $0.80 \mathrm{~m}$ and $2.34 \mathrm{~m}$ respectively; $\mathrm{m} 0$, mining thickness of mining layer, $6.5 \mathrm{~m}$; xi, is the original gas content of the i-th adjacent layer. due to the lack of gas content parameters of the adjacent layer, the design value is the same as that of the mining layer, $x i=3.24 \mathrm{~m} 3 / \mathrm{t}$; $x i c$, it is the remaining gas content in the adjacent $i$ seam, and the residual gas content of $2 \#$ coal is taken. xic $=2.60$ $\mathrm{m} 3 / \mathrm{t}$; $\mathrm{ki}$, it is the gas emission rate affected by mining in the $i$ adjacent area.

When mining $2 \#$ coal seam, there are mainly 3 or $10 \#$ coal in the adjacent coal seam. The distance between $3 \#$ coal seam and $2 \#$ coal seam is $1.87 \mathrm{~m}$, and the spacing between 10\# coal seam and 2\# coal seam is $44.26 \mathrm{~m}$.

Then, the gas emission quantity of adjacent layers can be calculated as $\mathrm{Q}_{\mathrm{L}}=0.31 \mathrm{~m} 3 / \mathrm{t}$.

3) Total amount of relative gas emission from mining face,

$$
\mathrm{Q}_{\mathrm{H}}=2.09 \mathrm{~m}^{3} / \mathrm{t}
$$

4) The relative gas emission in goaf is: ${ }^{[13]}$

$$
\begin{aligned}
& Q_{k}=Q_{H}-Q_{B}-Q_{l} \\
& Q_{B}+Q_{l} \approx x-x_{c}
\end{aligned}
$$

Formula: $Q_{k}$, relative gas emission in Goaf, $\mathrm{m}^{3} / \mathrm{t} ; Q_{B}$, relative gas emission of coal wall, $\mathrm{m}^{3} / \mathrm{t} ; Q_{l}$, relative gas emission of falling coal, $\mathrm{m}^{3} / \mathrm{t}$. According to the calculation, $Q_{k}=1.45 \mathrm{~m}^{3} / \mathrm{t}$.

The change of absolute gas emission from 322 working face is calculated when different daily output is calculated, as shown in Fig. 1.

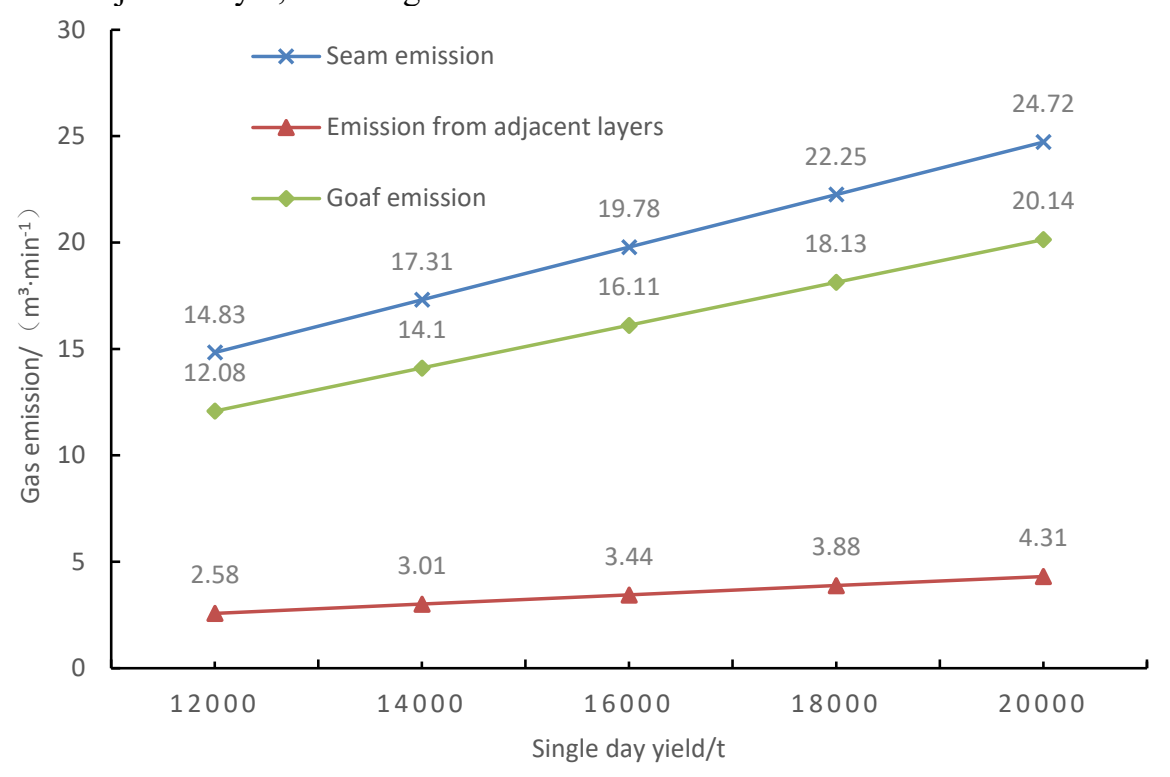

Fig.1 322 Curve of gas emission with productivity

It can be seen that with the increase of single production of ultra strong mining, the gas emission of working face increases continuously, among which the relative gas emission of mining coal seam accounts for $85 \%$ and that of adjacent seam accounts for $15 \%$. Among the gas sources of working face, the coal seam mined and coal falling released by shearer is one of the main gas emission sources.

According to the statistics and Research on the amount of gas discharged from the air, the gas emission from the goaf accounts for $40 \sim 50 \%$ of the total amount of air exhaust in the working face ${ }^{[13]}$, which is also the main source of gas emission, resulting in the high gas concentration in the upper corner.

Therefore, the main source of high gas emission in the fully mechanized caving face with low gas and super strength is the coal seam mining and the analytic release of adjacent seam superimposed in the goaf, which is the main reason for the gas concentration exceeding the limit in the upper corner area, and is also the focus of gas drainage and prevention. 


\section{Gas drainage measures in fully mechanized top coal caving face}

\subsection{Upper corner pipe inserting (buried) pumping technology}

Two drainage pipelines with diameter of $426 \times 3.6 \mathrm{~mm}$ are laid in the return air roadway of the working face, which are made of thin-walled steel pipes. The $\Phi 273$ $\mathrm{mm}$ pipeline is connected with the high-level directional drilling hole at the drilling site of the high-level directional drilling hole, and the $\Phi 426 \mathrm{~mm}$ pipeline extends to the upper corner position, which is specially used for gas drainage by intubation and buried pipe. The $\Phi 426 \mathrm{~mm}$ pipe is connected by a $6 \mathrm{~m}$ long steel pipe, with a fork reserved every $12 \mathrm{~m}$, and the upper end is connected with a vertical buried pipe. The pipe type is a sieve type pipe with a height of $2 \mathrm{~m}$ and a diameter of $\Phi$ $273 \mathrm{~mm}$. With the mining buried pipe entering the goaf, the gas in the upper corner of the goaf is extracted by negative pressure, and the flow field of the upper corner is changed, which directly reduces the gas emission in the upper corner, thus reducing the gas concentration in the upper corner. The DN250 valve is led out at the bifurcation, and the horizontal L-shaped cannula is installed. The horizontal position of the intubation is connected by a $\Phi 400 \mathrm{~mm}$ air duct. The whole section is fixed by hanging steel strand after the anchor rod is hoisted in the roof construction. It is inserted at the top cutting line position of the upper corner, which is about $1.0 \mathrm{~mm}$ toward the goaf At $\mathrm{m}$, with the advance of the working face, the position of the upper corner cannula is retreated synchronously, which makes the position of the upper corner basically unchanged relative to the cutting hole position of the working face. Continuous gas drainage at the upper corner position will directly affect the gas concentration in the upper corner.

\subsection{High directional directional borehole gas drainage technology}

High position directional drilling has become the main technical method of gas control in the upper corner of working face with the advantages of controllable trajectory, low construction cost, long effective hole section and wide coverage. The high-level directional drilling field was developed at the side of air return roadway, and the high-level directional drilling was implemented. The drilling track was arranged in the fracture space formed in the overlying strata during the mining process to achieve the purpose of gas drainage in the fracture zone.

According to the "three under mining regulations", the following empirical formula can be selected to determine the height of caving zone and fracture zone.

$$
\text { Caving zone height, } H_{M}=\frac{100 \sum M}{2.1 \sum M+16} \pm 2.5
$$

Formula: $H_{M}$, height of caving zone, $\mathrm{m} ; \sum M$, the thickness of the coal seam to be mined, $\mathrm{m}$.

$$
\text { Fracture zone height, } H_{L}=\frac{100 \Sigma M}{1.2 \sum M+2.0} \pm 8.9
$$

Formula: $H_{L}$, height of caving zone, $\mathrm{m} ; \sum M$, thickness of coal seam to be mined, $\mathrm{m}$.

Therefore, the height of high-level borehole should meet the following conditions:

$$
H_{M}<H_{s}<H_{L}
$$

The mining thickness of coal seam in the working face is $6.5 \mathrm{~m}$, according to formula (8), the height range of caving zone is $18.86 \sim 23.86 \mathrm{~m}$, according to formula (9), the height range of fracture zone is $56.78 \sim 74.58 \mathrm{~m}$, according to which, the vertical height of high-level directional drilling is arranged in the middle and lower part of $23 \sim 60 \mathrm{~m}$ fracture zone above the coal seam roof. The principle of horizontal distance between high-level directional drilling and return air roadway is that the plane projection of directional drilling in one drilling field covers about 1 / 5 of the working face length.

After the determination of drilling horizon parameters, ZDY6000LD directional drilling rig is used for drilling, and the drilling technology of "directional pilot hole + reaming" is adopted. The two-stage hole structure of $\Phi$ $101 / \Phi 133 \mathrm{~mm}$ is adopted for drilling, and the final hole diameter is $\Phi 133 \mathrm{~mm}$. Three to six high-level directional boreholes are designed in a single high-level directional drilling field. The fan-shaped layout method of layered dislocation is used to extend in the roof rock. Gas is extracted after the pressure of overlying strata is relieved after the cut-off of working face is carried out. The drill yard spacing is about $500 \mathrm{~m}$. The design depth of high-level directional drilling between drilling sites is $500 \sim 600 \mathrm{~m}$, and the overlap distance of drilling holes is greater than $50 \mathrm{~m}$, which can reduce the blind area of drainage and effectively avoid the fluctuation of pumping effect at the overlapping position. Ensure the normal production of mining face.

\section{Engineering practice and effect analysis}

\subsection{Application and effect of gas drainage by inserting (burying) pipe}

As shown in Fig. 2, on July 6, 15 and August 21, the high-level directional drilling was manually cut off or the pumping stopped due to the installation of high-level directional drilling. This method was used to investigate the pumping situation of single method of inserting (burying) pipes at the upper corner. It can be seen that after the single measure of inserting (burying) pipes at the upper corner, the net flow rate of gas drainage increases obviously, from $1.0 \sim 1.4 \mathrm{~m}^{3} / \mathrm{min}$ before, to $2 \sim$ $2.8 \mathrm{~m}^{3} / \mathrm{min}$, and the pure drainage quantity is greatly increased. However, the corresponding gas concentration in the upper corner also increased significantly, reaching about $0.8 \%$, which was in the lower edge of gas overrun value several times. Although the single upper corner pipe (buried) drainage method has obvious drainage effect, and the maximum pure gas drainage amount reaches $2.8 \mathrm{~m}^{3} / \mathrm{min}$, it has a positive effect on the gas prevention and control of the upper corner of the working 
face, but it can not fully guarantee the normal production of the working face.

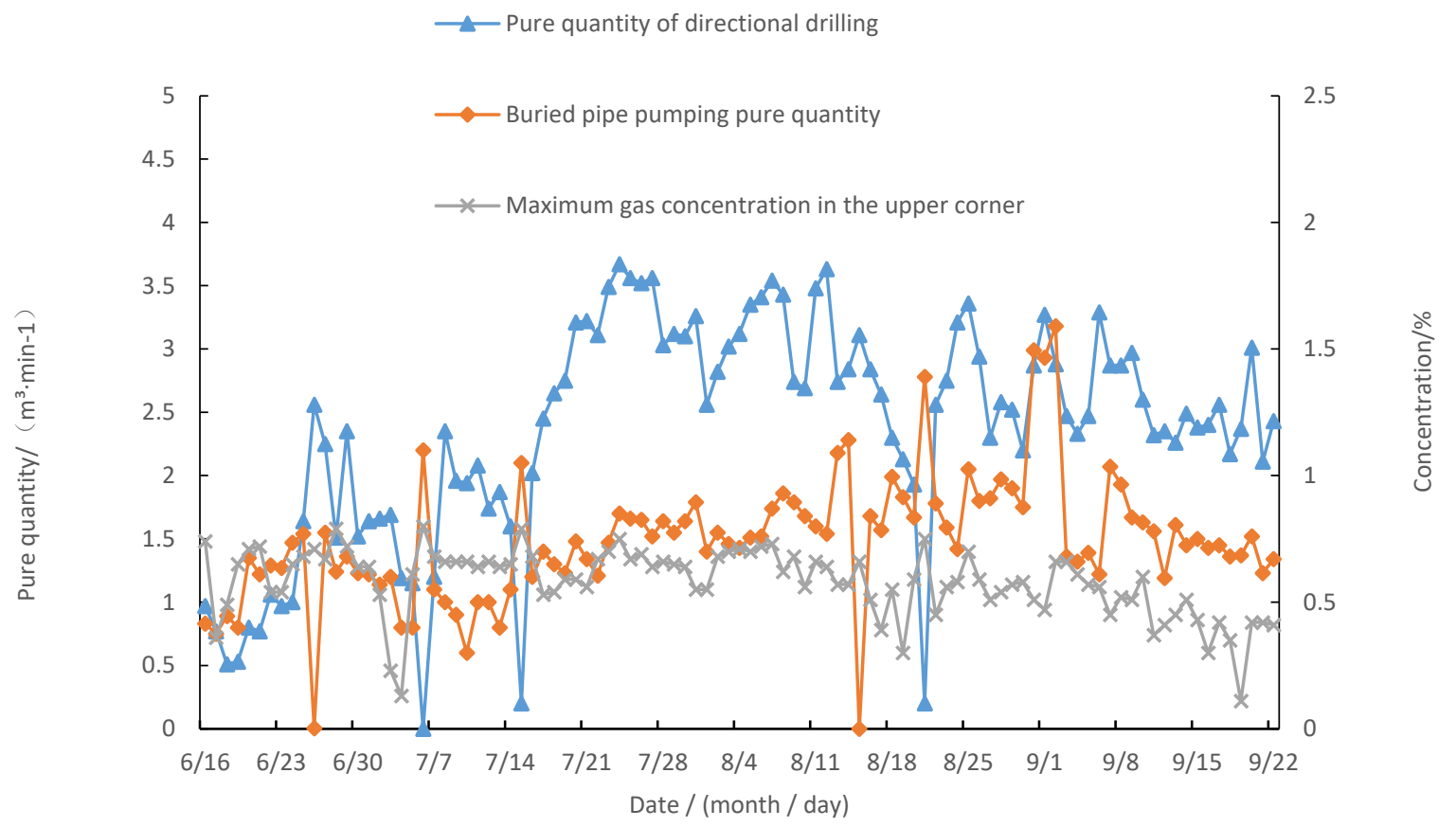

Fig.2 Effect of corner insertion (buried pipe) extraction

\subsection{Application and effect of high level directional drilling}

The1\#, 2\# drilling field is located at $424 \mathrm{~m}$ and $800 \mathrm{~m}$ of the return air lane, and 4 high directional drilling holes are arranged in the drill field. The borehole diameter is $\Phi$ $133 \mathrm{~mm}$, and the overlap section of high-level directional drilling in two drilling fields is $50-80 \mathrm{M}$. the trajectory of high-level directional drilling is shown in Fig. 3.
Fig. 4 shows the pure quantity curve of high-level directional drilling. The average extraction concentration of the four boreholes in No. 1 drilling field is $10.29 \%$, $7.24 \%, 8.25 \%$ and $2 \%$; the average extraction pure quantity is $0.77 \mathrm{~m}^{3} / \mathrm{min}, 0.56 \mathrm{~m}^{3} / \mathrm{min}, 0.73 \mathrm{~m}^{3} / \mathrm{min}$ and $0.33 \mathrm{~m}^{3} / \mathrm{min}$, respectively. The $1-1,1-2$ and $1-3$ boreholes have a large amount of pure oil extraction, and the high-level extraction time is long, so the directional drilling trajectory is a better horizon.

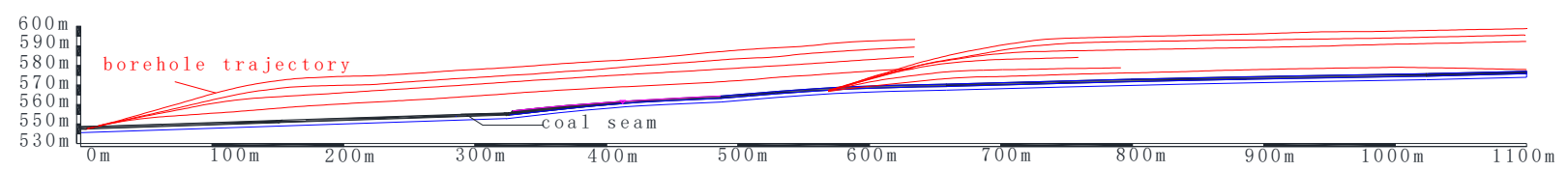

Fig.3 High-position directional borehole profile trajectory 


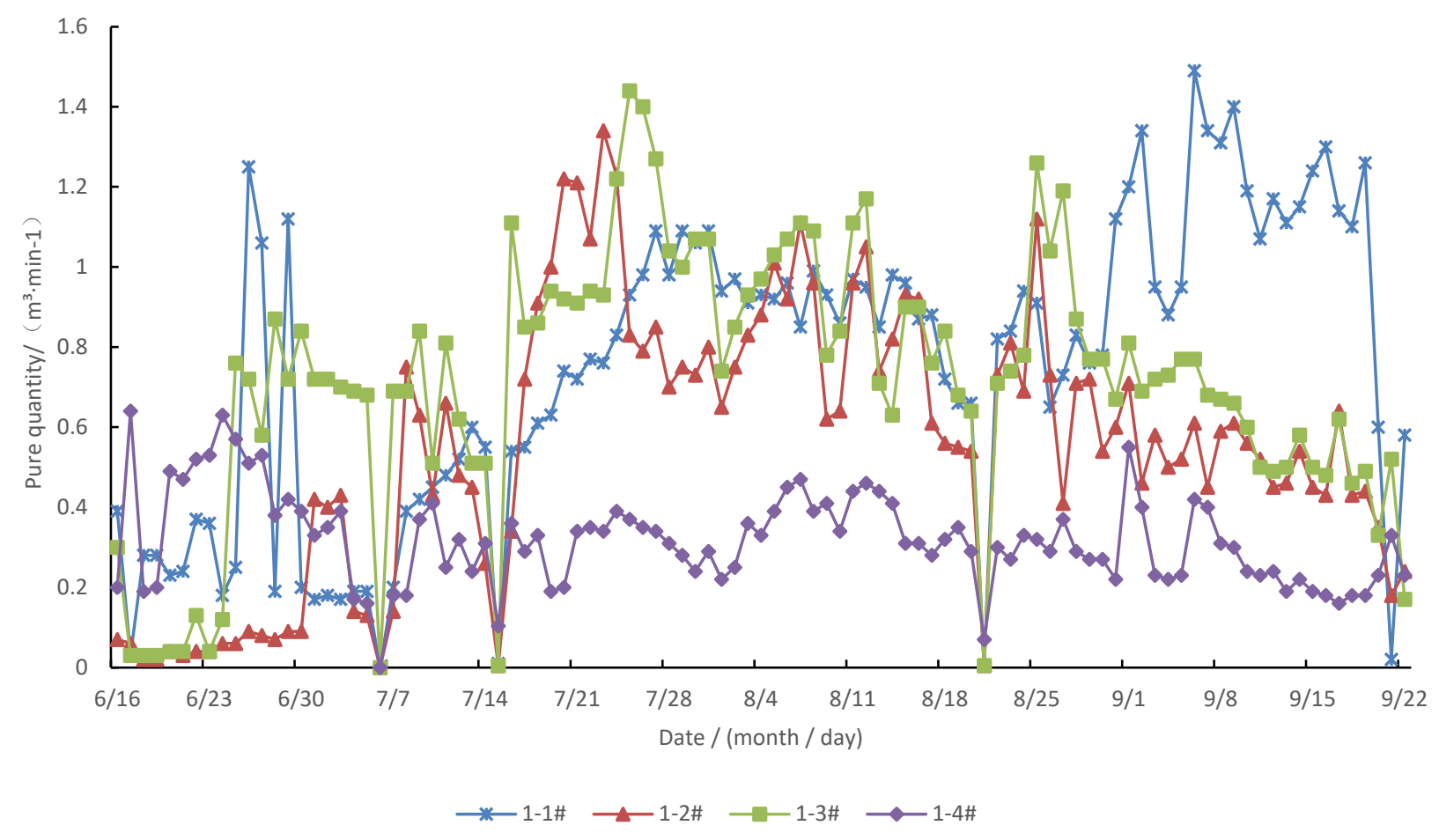

Fig.4 Pure Quantity Curve of High-position directional borehole Extraction

As shown in Fig. 2, in the comparison of gas concentration of high position directional drilling main pipe drainage, upper corner pipe inserting (buried) drainage and upper corner gas concentration, the influence of single drainage method on gas concentration in upper corner is compared by using the manual closing of upper corner inserting (buried) pipeline on June 26 and August 15. It can be seen that after the upper corner pipe is closed, the drainage effect of high-level directional drilling is improved to a certain extent, and the pure extraction amount is increased to $2.56 \mathrm{~m}^{3} / \mathrm{min}$ and $3.11 \mathrm{~m}^{3} / \mathrm{min}$ respectively However, the growth of the data is mainly caused by the change of high-level directional drilling data, which has a low correlation with the closing of pipe (buried) drainage. At the same time, the volume fraction of gas in the upper corner also increased to a certain extent, up to $0.71 \%$. High level directional drilling has a good effect on gas drainage in goaf with large amount of drainage. However, there is no direct interference measures in the upper corner position, which leads to the gas concentration in the upper corner rising obviously.

\subsection{Analysis of collaborative pumping effect}

As shown in Fig. 5, the total gas drainage net amount, the gas concentration in the upper corner of the working face and the return air flow are in direct proportion with the increase (decrease) of the daily advancing distance of the working face. From June 17 to June 27, the daily advancing distance of the working face gradually increases, and the total gas drainage pure amount, upper corner and gas concentration of return air flow in the working face have an obvious upward trend.

With the steady increase of the total amount of collaborative extraction of upper corner pipe (buried) and high-level directional drilling, the gas concentration of upper corner and return air flow fluctuated greatly from the beginning stage to the stable range, the concentration of upper corner was $0.55 \sim 0.75 \%$, the concentration of return air flow was $0.29 \sim 0.48 \%$, and finally entered the descending range, that is, the concentration of upper corner decreased to $0.31 \sim 0.61 \%$, and the concentration of return air flow decreased to $0.27 \sim 0.40 \%$. The effect of gas drainage and control in super strong mining face is obvious. 


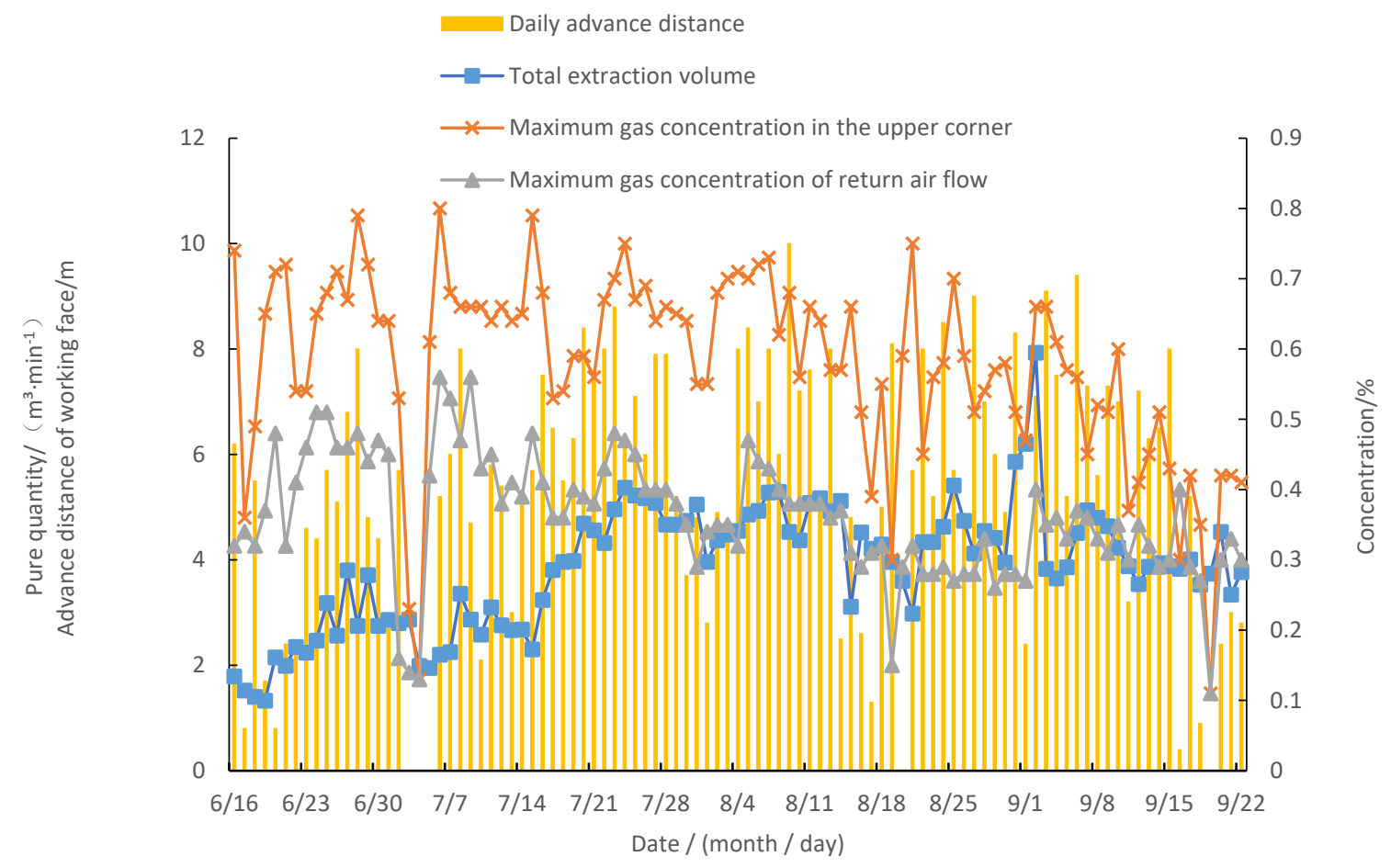

Fig.5 Propulsion distance, total extraction purity, upper corner and return air flow gas concentration curve of working face

\section{Conclusion}

The main source of high gas emission in fully mechanized caving face with low gas and super strength is the coal seam mining and the analytic release of adjacent seam superimposed in goaf, which is the main reason for the gas concentration exceeding the limit in the upper corner area, and is also the key point of gas drainage and prevention.

The adoption of single drainage method is helpful to reduce the gas concentration in the upper corner of super strong mining face, but it can not completely eliminate the hidden danger of gas parameter overrun. It is the key technology to ensure the safe production of working face that the gas drainage method of upper corner inserted (buried) pipe and the gas drainage technology of high-level directional drilling.

Super full mechanized top coal caving face adopts the technology of upper corner insert (buried) pipe extraction and high position directional drilling to extract synergistic gas, and the maximum extraction volume of working face is $7.93 \mathrm{~m}^{3} / \mathrm{min}$. The results show that the gas concentration in the upper corner is reduced to $0.31 \sim$ $0.61 \%$ and the return air flow concentration is reduced to $0.27 \sim 0.40 \%$, which effectively solves the problem of gas overrun in the upper corner of super strong fully mechanized caving face, and also provides technical ideas and practical basis for gas prevention and control in this type of super strong mining technology mine and working face.

\section{Funding}

This work was supported by the National Key R\&D Program of China (Grant no: 2018YFC0808202), and Major special project of science and Technology in Shanxi Province (Grant no: 20181101013).

\section{Reference}

1. Dong H.K. Application and establishment on evaluation system of gas drainage and outburst prevention to high outburst mine $[\mathrm{J}]$. Coal Science and Technology, 2016, 44(2) : 84-88

2. Wu B., Lei B.W., Hua M.G.,et al. Parameters of gas tube extraction technology in the upper corner of working face[J]. Journal of Mining \& Safety Engineering, 2014, 31(2) : 315-321

3. Wang W., Cheng Y.P., Yuan L., et al. Floor fracture evolution and relief gas drainage timeliness in deeper underground short distance upper protective coal seam extraction[J]. Journal of China Coal Society, 2016, 41(1) : 138-148

4. Zhang Y., Zhang C.L., Zhao F. Dynamic evolution rules of mining induced fractures in different floor area of short distance coal seams[J]. Journal of China Coal Society, 2015, 40(4) :786-792

5. Yin G.Z., He B., Li M.H., et al. Coupling mechanism between flow rate of gas drainage and coal seam abutment stress under mining 
conditions[J]. Journal of China Coal Society, 2015, 40(4) : 736-741

6. Hu Z.F. Regional gas control scheme and effect analysis[J]. Industry and Mine Automation, 2018, $44(8): 19-23$

7. Wu Y.G., Wu J.M., Wang J.F., et al. The law of gas distribution in goaf of fully mechanized top-coal caving working face with "double-U" ventilation system[J]. Journal of China Coal Society, 2011, $36(10): 1704-1708$

8. Wang Z.F., Guo L.C., Su W.W., et al. A quantitative analysis method of gas emission source based on gas daily report in working face[J]. Journal of Henan Polytechnic University: Natural Science, 2015, 34(3) : 311-315

9. Hu S.Y., Zhang J.L., Feng G.R., et al. Research on methane enrichment mechanism in coal mine goaf[J]. China Safety Science Journal, 2016, 26(2) : 121-126

10. Tu S.H., Zhang C., Yang G.Y., et al. Research on permeability evolution law of goaf and goafpressure-relief mining effect[J]. Journal of Mining \& Safety Engineering, 2016, 3(4) : 571-577

11. Cui H.Q., Fan S.H., Guan J.F. Calculation of methane emission from different sources at coal mining face based on monitoring data[J]. China Safety Science Journal,2014,10(7) : 78-83

12. Zhang L.L., Li C.Y., Li X. Some Calculation Methods of Gas Outflow From Worked- out Area[J]. Coal Technology, 2007, 26(8) : 71-72

13. Hao G.S., Chen B., Shen K. Analysis on differential layout and gas drainage effect of high position directional borehole in roof of goaf[J]. Coal Science and Technology, 2018, 46(8) : 101-106 